DOI:10.21776/ub.icon_laterals.2016.001.1.15

Reading Butlerian Gender: an Autopsy through Film Predestination (2014)

\author{
Dwi Lisa Susanti, S.S., M.A. \\ Respati Yogyakarta University \\ Yogyakarta, Indonesia \\ dwilisas@yahoo.com
}

\begin{abstract}
Gender and sexuality became a sensitive worldwide issue. It began with traditional feminist view believing sex is a biological category while gender is a historical category - meaning that gender is socially and culturally constructed. This view did not change until Butler, with her contemporary thought, emerged and became a new colour in feminist field. With he concept of performativity, she argues that gender is not a necessity which express sexed body, it is rather a sequence of performance, a choice. Due to the dynamic change of those views, literature becomes a war machine against the concept of binary gender and sexuality. This can be seen in a 2014 film directed by Michael and Peter Spierig, Predestination, which narates how sex and gender are played by an institution. Using a time travel-machine in a mission preventing Flitzer Boomber's terror, the main character meets with some characters of himself in the past. The change of himself from man becoming woman and also an intersex shows author's project in voicing equality. It is a critic addressed to the concept of binary gender-showing gender instability. But the question is, if institution becomes a motor in this mission, meaning that institution or certain group of interest constructs subject's unconsciousness to be gendered and sexed, is this a real campaign in the name of humanity or instead it turns to be other hierarchy of how being LGBT with flaw? Thus, this analysis aims at seeing how far undoing gender works as depolitical critic to gender.
\end{abstract}

KEYWORDS: sexuality, gender, intersex, equality

Intersex, with all complicated political states, comes with all problems and it is because of its gender trouble instead of its biological term as nature. Sex is typically associated to the construction of gender and it is traceable to the long-established 
edifice constructing a steady erection of understanding. Butler many times states in her early part of his book, Gender Trouble;

Are the ostensibly natural facts of sex discursively produced by various scientific discourses in the service of other political and social interests? If the immutable character of sex is contested, perhaps this construct called 'sex' is as culturally constructed as gender, indeed, perhaps it was always already gender, with the consequences that the distinction between sex and gender turns out to be no distinction at all (Butler, 1990: 7).

Butler's questions refer to how the general understanding pinpointing gender as category taking-for-granted from the genital. This composure nails an orthodox perspective that sex and gender are same. It is unquestionably an individual identity. For instance, an individual having penis, the gender must be masculine with all attributes and an individual having vagina, the gender is feminine with all attributes. This constructive binary perspective indirectly abandons anything outside of it, no exception for an individual having double sexes, or customary todays called as intersex. Old-school perspective categorizing sex and gender are same, but the existence of intersex disrupts the structural construction of the binary gender. Intersex intervenes with the contradictory two genitals, thus it cannot be classified into a gender.

An individual having double sex can be either he or she, and even both. Intersex can be either male or female and even neither both. Yet, the perspective, previously, with its orthodox view, even elucidates that there are only two genders, male and female and only two sexes, penis or vagina. This strict border constructs subjects' unconsciousness to be in one and if it is intersex, it should be put on a treatment or 
even a sexual surgery. Consequently, as Preves' statement, "we are walking carriers of the gender questioning disease" (2003: 125)

This is just what we are afraid to know about the fact of gender as naturalillusive construction. We are just performing what the structural construction has nailed to us and we reproduce it. But, getting to the worse, film Predestination (2014) gives the practical example of how our unconsciousness is used by a sort of institution and the subject is practically performing a gendered composition and being played with it. This film explores an attempt to prevent the bombing caused by a man called Fizzler Bomber. An agent is sent to overcome it and with a time machine, he is asked to go time traveling in order to prevent the bomber bombing. In this traveling time, the agent, John, finds himself as women, named Jane. In a complicated plot, the young John is known to have relation with Jane, who is himself in another life. At the beginning, John is a female, then she is known to have intersex problem after bearing a child who is the child of Jane and John. The baby grows up as a girl and she meets John and this cycle concludes in an assumption that the intersex comes from the incest sexual relation (Jane and John is one person in different time-Jane does sexual surgery to become a man and this male body leads him to be the agent). The utmost surprising thing is where John finds himself as the bomber and this makes an analogical cycle that a snake chases its own tail.

Here are the points: (1) the agent is analogous to subject; (2) the space corps is analogous to social construction; (3) the subject does not what he or she is doing; and (4) subject is gendered, even sexed, by the space corps. Points 1 to 2 can be accepted without any critical pivotal issues because it is just the guide to read how this analysis starts with. Point 3 should be envisaged into a crucial idea. What we call as subject refers to an individual inseparable with social construction. This inseparable liaison 
does not negotiate subject by a means of that subject is subjected of it. Subject cannot unleash this tightly relation and even psychologically, what subject desires is always tightly what the other subjects want to the subject. Therefore, subjects' unconsciousness, willy-nilly, are chained socially. The problem is, subject is not conscious to be gendered. Subject just does perform the social construction over gender. The simple practice is through looking the sex, if there is laid penis, the individual is under social treatment to become a male (parents give male name, wear him the male dress and behave him to be a male). At this state, the baby, with all unconsciousness and the process of identification, just grants it without any rejection. And after all, he reproduces it and becomes his gender. This explanation indirectly discloses the point 4 that the subject does not even realize that he or she is subjected and gendered into one singular gender based on the sex.

By this encounter, this may render something that this film expounding the account of an intersexual-incest protagonist in some complicated conflicts (such as gender distributions, genital surgery, politicized unconsciousness), circuitously incriminates the questionable gender. This prejudice is also persistent, sustained by what Judith Butler elucidates that gender cannot be merely recognized only by classifying the sex(es). It is a discourse regularly acted by the subject while the subject does not know why he or she has to do it (the performance). Butler clarifies that "gender is not a noun but it proves to be performative, that is, constituting the identity it is purported to be. In this sense, gender is always a doing, though not a doing by a subject who might be said to pre-exist the deed" (Butler, 1999: 25).

Butler considers that there is no subject in the pre-discourse. There is only discourse contributing to the construction of gender. Subject is unconsciously subjected by the discourse which is reproduced. This reproduction in repetitive 
performance she calls as performativity; regular performances. Butler suggests that everything relates to gender is always about the construction of the discourse constructing its meaning structurally. Gender is early perceived from its genital and the ambiguous genital (intersex) has to be normalized by doing surgery. After all, the gender can be (re)located between man and woman, no other than it. Therefore, what subject performs daily, such as wearing bra is actually something constructive. Subject is unconscious to what they do. Subject is unaware of why they perform these gendered attributes. Just because it is regularly performed throughout subject's process of identification, subject cannot deny it. A baby is taught, learned and educated to be like what the society wants, if subject has penis, it is man, if subject has vagina, it is woman.

The reproductive performative gender of subject through binary sexual category uninterruptedly floods subject's unconsciousness, it affects the subject to do so. Subject follows what has been nailed in its unconsciousness, for instance, a girl with vagina is asked to wear bra and she must obey it without any protest). Butler cites what Nietzsche salutes in his book, On the Genealogy of Morals that "there is no being behind doing, acting, becoming; the doer is merely a fiction imposed on the doingthe doing itself is everything" (Nietzsche, 1998: 29). The origin of gender cannot be situated or located and it is even not stable in one steady term to define because woman can cut her hair to short and man can cook as woman, nothing is stable. The stability of the binary meaning between man and woman just ends in the borderless lineage. All attributes stated to separate between men and women cannot provide any stable frame scope and it is just a construction and no construction is non-destroyable. Accordingly, this unsteadiness reconstructs the concept of gender; genital or sex are just discourse and those are not the root of gender construction, it is just the repetitive performances unconsciously. 
As it is replicated in the film, the agent is gendered and (s)he just performs what "destiny" destined to him/her. The agent experiences of being (fe)male, intersex and even incest of his/her own self. This is a perfect situation to analyze the problem of gender, how it constructs our consciousness and how it is working on us. Since we are living surrounded socially, we cannot release social construction and this film replicates this situation rightly when the agent knows that (s)he is being played by Robertson, the space corps boss.

\section{FINDINGS AND DISCUSSION}

To start with, the discussion of this film encompasses three important issue about gender todays; (1) the misunderstanding conception between sex and gender, (2) how gender is constructed through performance and performativity, and (3) intersex as undoing gender. These three can be scrutinize deeply through the film Predestination since it is known that this film cycles these all into one crucial issue to bring up.

\section{Sex and Gender: a Misconstruction}

Because the focus is not on the account of the paradoxical time-traveling, it therefore underline the cases occurred throughout the going-forward plots. Started in 1945, a year when Jane was born. Jane was stolen and laid in front of an orphanage. She was raised there with all female attribute. She grew up with self-questionable about male inside of herself. She decided to apply at Space Corps after recommended by Robertson. At the physical test, Jane was so superior but the board found Jane's unique case which ruined Jane's hope to join there. At this part, it can be known clearly that Jane was constructed to become a female instead of male during the living in the orphanage. This construction, of course, disturbs something male inside of her body, but Jane should obey the social construction given to her to become a female instead 
of a male. The simplest thing to catch is that young Jane owns vagina and her penis has not grown well. This vagina constructs Jane and Jane is insisted to swallow how to become a girl. This is how gender and sex, in orthodox way, snatch subject in a tight chain.

Gender is a crucial issue always brought to discuss in the study of feminism. But, there is something irritating to know that gender is always related with sex instead of claiming it as a social construction. Furthermore, sex (as gender) is envisaged as a biological, natural and unmovable condition. This value continuously relates to the attributes dividing masculinity for men and femininity for women. It is prominent to see that Butler ostensibly articulates the idea about the contribution of (social) discourses headed for the construction. For her, gender and sex have no tight relation at all. As described by Sara Salih, Butler abandons the universal supposition that sex, or gender, or even sexuality, independent from each other; Salih continuous that "Butler departs from the common assumption that sex, gender and sexuality exist in relation to each other" (Salih, 2002: 46). For example, a person is physically expressed as a woman because of having vagina. She is projected to perform the performance and character of being womanlike and devouring a sexual interest in men. It should be reproduced in the daily life until it creates the stereotype of female. While a subject is determined to be a man or a woman from the sex and after that, the gender claws its attributes. Therefore, these all connect to each without subject's consciousness. It means that there is nothing behind what they are doing and there is no nature behind a gendered subject. In simple word, Butler sees that both gender and sex are something that constructive and artificial. There is no relationship between the gender and the biological body. There is no strict rule that says a person can only be female or male. 
This indication refers to what Beauvoir's conception that "one is not born, but rather becomes, a woman" (Beauvoir, 1972: 295). Butler agrees to this assertion that one is not born but rather becoming, particularly in the notion of woman's condition. Women are constructed from outside or the exteriority it can be laws, surroundings, patriarch society and so on. Consequently, a woman must be(come) the woman and it is not her. Butler and Beauvoir perceive that gender is not only determined since birth, but also constructed through a repetitive and regular process of performances. Butler values Beauvoir to look at the dichotomy between men and women as separation category. This binary category locates women as the subordinated, marginalized and even inferior below men. Beauvoir focuses on the binary categorization. On the other hand, Butler focuses on how this binary construction constructively constructs one's unconsciousness. She questions the discourses behind the category. For Butler, what Beauvoir focuses just become the obsession among feminists toward the category, while the category is tantamount to reducing the diversity of gender identity into a limited concept in which only a few individuals who can enter into it. Butler asserts that it is the "[...] time to entertain a radical critique that seeks to free feminist theory from the necessity of having to construct a single or abiding ground" (Butler, 1990: 7).

Here, this can be emphasized that Butler belligerently endeavors to explain that subject is absolutely constructed, so are gender and sex. Seeing gender is constructed means the unnatural side of it and when it is related to sex, the differences are questionable but the same crystalized to a peaking summit; both gender and sex are just discourse or text. In these radical circumstances gender does not depend on sex, gender is "a free-floating artifice" (Butler, 1990: 6). For Butler, "sex is as culturally constructed as gender; indeed, perhaps sex was always already gender, so that sex/gender distinction is actually not a distinction at all" (Butler, 1990: 7). Both sex 
and gender are constructive and the two are always already related each other, like the chain of signifiers. This make impossibility to elucidate that gender is only known by the sex because sex itself is also known by other infinitive signifiers.

This is the way poststructuralist thinks, such as Jacques Derrida. He salutes that "there is nothing outside of the text [there is no outside-text; il n'ya pas de hors texte]" (Derrida, 1997: 158). There is only nonexistence behind the object which is signified but chain of signifiers. All is discourse and all discourse is the text. The text is language and language is system of signs. In signs, there is no signified because the signified is always already signifiers. There is nothing meaningful without being in language. We cannot understand something if only it is not in language. Our mind and even unconsciousness is set to be in language. Outside of it, it is something beyond and transcendental to understand. This is what occurs in sex. It is categorized into two categories by a means giving meaning beyond the category (meaning of man and woman) while to catch the meaning, we need to relate it with other signifiers such as the characteristics and the attributes. For example, penis is just a physical object but it becomes meaningful when it is juxtaposed and compared to vagina. The opposite differences create the category and create the meaning. Therefore, the meaning of sex is actually coming from the comparison, not the object itself. It is what so called as the construction. All people do it until they cannot realize what they are doing behind this fictive construction. Sex is only discourses of texts and signifiers without its meaning, "sex as a material or embodied difference between male and female only has meaning within the cultural framework that in the sex/gender distinction it is otherwise imagined to precede [it]" (Brady \& Schirato, 2011: 34).

Looking up the idea of the compound of signifier and signified in the language, sex is just a signifier to create otherness and this otherness creates the fictive meaning 
of the subject. Nevertheless, this scheme of signification fails simply because there is just process of constructing the other signifiers. It is just a construction and construction is representation of limitless representations. Conclusively both sex and gender are discourse; it is construction and unstable text. This is what previous feminists forget because they were trapped in the category and they reproduced biological aspect as gender problem. Butler looks to intricate it;

According to traditional feminists, sex is a biological category; gender is a historical category. Butler questions that distinction by arguing that our "gender acts" affect us in such material, corporeal ways that even our perception of corporeal sexual differences are affected by social conventions. For Butler, sex is not 'a bodily given on which the construct of gender is artificially imposed, but [...] a cultural norm which governs the materialization of bodies (Butler, 1993: 2-3).

Butler keeps looking that sex is a physical determined by gender attributes instead of the cultural norm. For example, a woman (with vagina) is constructed to be a woman, feminine, sexy and flirting and other attributes. The value of cultural practice unceasingly maintains the woman to behave it. This constructive sex is regularly performed by the woman (making up, polishing powder, drawing eye-shadow, consuming cosmetics and so on). This shapes the unconsciousness and of course, she will deny stopping performing it. Something given finally becomes more than the subject herself. Subject always become the subject of a constructive discourses. The key point should be wizened is the mode constructs subject. Sex is unnatural thing, but a constructive discourse taken from gender while gender itself is also a constructive discourse. Gender is always already constructed by the discourse flooding the space of 
meanings. Language and discourse affect to subject's unconsciousness and both gender and sex just refer to the performance and performativity.

\section{Performance and Performativity}

It is simply enough to look up the plot bringing Jane/John to follow the life. Jane who had grown up as a woman decided to try to join the Space Corps. As it has been inclined previously, Jane passed all tests until she was found by the board to have something failing her. In this difficult moment, Jane tried to keep her life by being a babysitter while she studied in a manner school. In this school, Jane ought to learn how to be a real wife and of course, in this school, Jane met Young John (who was herself). The point is, Jane was strongly enough to perform becoming like a total woman although she has to fight against male side inside of herself. This is the problem of performativity, with regardless who she is, a woman should be able to perform womanlike to become woman. Therefore, woman and men are just becoming, not being, and this introduces the problem of gender as the problem of performativity and performances.

Butler introduces performativity to expose gender as a regular performance. Gender, Butler says, "is a process which has neither origin nor end, so that it is something that we do rather than are" (Butler, 1990: 46). It is the regulation produced frequently and constantly by the subject thus it exists from its repetitive doings. Likewise to signs, there are only signifiers in process, what subject does is just because what subject must do, not because there is something essential behind it. The doing refers to other doings. For Butler, gender based on performativity refers to a process of a construction and therefore, "gender proves to be performative - that is, constituting the identity it is purported to be. In this sense, gender is always a doing, though not a doing by a subject who might be said to pre-exist the deed" (Butler, 1990: 
25). For example, a girl wears bra. At the beginning it has function to sustain and to cover the nipples, but accordingly, this turns to be the identity and it becomes more than its functions like we are seeing bra with expensive prices and accessories. The way they own the identity, particularly their gender, is really constructive. At this case, subject truly has a choice to choose or not choose, but subject is subjected to one singular gender. Butler ensures that gender is unnatural thing because it is a choice and subject can abandon it (gender is a choice) (Butler, 1987: 128-129) and in a way subject chooses a gender, the gender forever always exists in subject's construction and identity. After all, subjects just perform the performances of a gender and that is how gender is only the acts of what subjects perform. These consistent acts are called as the performativity, as Butler says, "in my view, performativity is not just about speech acts. It is also about bodily acts" (Butler, 2004: 198.).

Gender as performance refers to a process occurring constantly and to an unsteady condition. The concept of a steady gender identity is simply a delusion because the structure of dichotomy gender refers to discourses without any steady matter. The categorization blurs out, men can be feminine and so can women. The categorization is just concept and illusion perpetuated by the binary opposition and Butler tries to weaken this traditional design in a critical evaluation, especially about the hierarchy. Here, Butler seems to impose deconstructive reading on gender. Conclusively, gender should be noted as a process in repetitive, continuous, unstable process. This is similar to what Salih adds, "crucially, Butler is not suggesting that gender identity is a performance, since that would presuppose the existence of a subject or an actor who is doing that performance. Butler refutes this notion by claiming that the performance pre-exists the performer" (2002: 10). 
Butler has expounded subliminally the way subjects animate as actors who perform the role. Subjects cannot avoid the destined role as the cast which is demanded. The actor acts without action because surely there is just actor without act. The act is just a bogus imagination performed by the actors and of course, there is nothing outside of what the actors performs. It is just acting. So, performance does not exist without the performer and the performer is the very responsible for the existence of the performance they do. The spectators just watch what is performed and they do not care behind it. The concept of performance and performativity is like a baby wears a cloth. Absolutely, the one(s) who set it up is the parent and whatever the parents give to the baby, the baby just nodded like a dog. The baby is unconscious of wearing it until the baby regulates it to be his or her identity. Here is important to resolute, gender is constructively given and after that, subjects are regularly acting and doing it. It develops to become the performance until this performance becomes the performativity in repetition regularly. Hence, "performativity not as the act by which a subject brings into being what she/he names, but, rather, as that reiterative power of discourse to produce the phenomena" (Butler, 1993: 2).

\section{Intersex as Undoing Gender}

Jane and John are one person and the complicated plots give a fuzz to know that John and Jane have sexual relation and therefore they have a baby (Jane) who at the grown age is known as an intersex. In the simple word, Jane and John are in incest relation. Let us skip a perspective seeing this as sinners, because there once important point to envisage; the intersex Jane. After Jane gave the birth for young Jane, Jane was sentenced to have double sexes in which the penis is still in process to grow. The doctor suggested Jane to do sexual surgery for becoming a man. After becoming a man, Jane changed her name to John. John tried to join the Space Corps and became the time- 
traveling agent in which he has to pursue himself. Here is the crucial point to see, the intersex Jane finally abandons herself to let her male side takes over herself totally. For the social structure, something happened to Jane is actually a disease, abnormality and outsider. Therefore, Jane should be normalized to determine her gender and of course, to be able to become an agent which requires male category.

Intersex is a disorder of gender exposing the ambiguous category between male and female. Ambiguous condition denotes to the in-between location, (n)either male (n)or female because the intersex owns two sexes in a body. Tyler Lopez in www.slate.com notes that intersex is an unusual birth with unidentified sex which makes difficulty to classify individual gender;

An intersex individual is simply someone born with sex characteristics that do not allow them to be defined as distinctly male or female. It is a totally natural, not infrequently encountered medical condition. Studies have estimated that as many as 1 in 100 children will be born with bodies that "differ from standard male or female." It is estimated that 1 or 2 in every 1,000 intersex individuals will undergo surgery to modify genital appearance" (Lopez, 2014).

Intersex is demarcated as like an abnormal case, an odd birth, or even unfamiliar case for individual to accept. Two genitals in a body cause this surprise because social structure only knows a sex in a body. Thus, intersex generally is seen as violence for social structure and an intersex must be under social violence if only (s)he does not determine the sex to choose by doing sexual surgery to normalize. At this part, the right is put at stake. The right living freely is oppressed and social norm seems to jail instead of freeing. Man and woman are just how social structure constructs us. In 1933, Sigmund Freud once said that "when you meet a human being, the first distinction you 
make is male or female? and you are accustomed to make the distinction with unhesitating certainty" (Freud, 1933: 113). Freud exposed the critical idea about male and female; those are identified just because society determines it unconsciously. Catherine Harper in her book entitled, Intersex, even enflames a thought-provoking notion that;

[...] intersex as taboo, a counter to 'infant purity'. Uncertainty of sexespecially in the newborn-activates parental and cultural shame, guilt and panic. Faced with a 'hermaphrodite' baby, many parents find it intolerable that their child is neither boy nor girl. They fear for their infant's future, and they fear for themselves. The drive to surgically 'normalize' the genitalia of those infant intersexuals whose genitals diverge from a familiar norm is arguably connected to a desire to dispel the force of uncanniness, with its associations of superstition, deathliness and negation (Harper, 2007: 2).

Intersex is considered as a victim of the social norm whose gender is in a category. Social structure does not stand by the unusual case of an intersex. The intersex should be normalized into a gender as she enhances that "there may be internalized gonads that contain both ovarian and testicular tissue mixed together. Similarly, or in addition, genetic configurations and hormonal balances may be atypical for a regular male or female" (Harper, 2007: 9). This can be streamlined to simplify that intersex is "a blend of both male and female internal and/or external genitalia" (Creighton, \& Liao, 2004: 659).

\section{Intersex and Gender Trouble: Politicizing?}

In Butler's sight, gender discrimination occurs in women for decades and it still remains up todays including in the matter of Transsexual, Intersex, Transgender, Lesbian, Gay and Bisexual (LGBT). For Butler, intersex activist movement opposing 
the practice of genital corrective surgery on babies born with intersex conditions on the name of normalization, cannot be put on the rightest or the holist side, because they can make it as a political interest.

In the case of John and Jane, (s)he does not realize that (s)he is under the control of Robertson. The Space Corps has played it all and the subject cannot realize. John feels that he can save the bomb while he is the bomber. It is like what happens todays where LGBT people think that they can save their own right, they simply can split and turn to be another ideological wave. At the beginning, the Space Corps company functions to save the world, but go further to be a testing program for time machine. LGBT, at beginning, functions to save the right of LGBT, but it goes further to become a lifestyle and political tool; we save the LGBT, we will get the sympathy of equality. Ultimately, LGBT becomes the new society which potentially marginalizes the "normal" gender. It is just the problem of authority; who has the power, it will have the all.

On the further view, Butler exactly understands this movement, especially to intersex, as an effort to launch a sympathetic movement that individuals with intersex conditions are the part of humanity biologically and ethically. They should have the same treatment in social life. They can develop similar prospective talent the normal gender. They also have the same chance and opportunity to live like people generally. They should not experience a series of genital repair surgery just because this procedure exactly reveals the violence toward human's right. The intersex can become the extensive practice of performing intimidating surgery on infants and progenies with sexually unspecified or hermaphroditic anatomy in the name of normalizing. These bodies can propose a critical standpoint on the version of the human that human does not require ideal morphologies and the pressuring of physical and bodily norms. 
The intersex opposition to the widespread practice of performing coercive surgery on infants and children with sexually indeterminate or hermaphroditic anatomy in the name of normalizing these bodies offers a critical perspective on the version of the "human" that requires ideal morphologies and the constraining of bodily norms. The intersex community's resistance to coercive surgery moreover calls for an understanding that infants with intersexed conditions are part of the continuum of human morphology and ought to be treated with the presumption that their lives are and will be not only livable, but also occasions for flourishing. The norms that govern idealized human anatomy thus work to produce a differential sense of who is human and who is not, which lives are livable, and which are not. This differential works for a wide range of disabilities as well (although another norm is at work for invisible disabilities) (Butler, 2004: 4).

However, the issues of gender identity and sexual which are evoked and demonstrated precisely determine intersex to become more complicated. Intersex activist movement does not stop only at the level of refuse genital repair surgery because, basically, the problem of intersex is not always about a matter of form physically sex, but also about gender identity. When an intersex decides to choose a gender identity, it means that (s)he must be able to control social norms which are attached to it. When he turns to be male he has to perform as a male and when she has to be female she has to perform as a female. In other words, the decision to choose which gender and body as the identity that you want to use even gives the paradox in its process. It determines the highly risk which is going to happen in the transsexual subject of intersex just because subjects cannot release the influence of the society such as the norm, critique, and social transformation. For Butler, there lies the 
importance of determination of an individual in determining his identity and subject should release all oppression about gender because gender is unstable, it is just a construction and subject can break this all up.

Choosing one's own body invariably means navigating among norms that are laid out in advance and prior to one's choice or are being articulated in concert by other minority agencies. Indeed, individuals rely on institutions of social support in order to exercise self-determination with respect to what body and what gender to have and maintain, so that self-determination becomes a plausible concept only in the context of a social world that supports and enables that exercise of agency. Conversely (and as a consequence), it turns out that changing the institutions by which humanly viable choice is established and maintained is a prerequisite for the exercise of self-determination. In this sense, individual agency is bound up with social critique and social transformation. One only determines "one's own" sense of gender to the extent that social norms exist that support and enable that act of claiming gender for oneself. One is dependent on this "outside" to lay claim to what is one's own. The self must, in this way, be dispossessed in sociality in order to take possession of itself" (Butler, 2004: 7).

Furthermore, Butler suggests that subjects do not need to get stuck on gender identity and sexual categorization because it is more important to see that intersex activists' aim is to understand the norms or conventions which support individuals to live independently so that the norms or conventions which restrict their lives can be erased. Butler gives an example, in relation to the intersex movement, to determine an intersex social identity and it means that a subject does not mean we have to follow rules that require genital repair surgery. 
Although a child should be given a sex assignment for the purposes of establishing a stable social identity, it does not follow that society should engage in coercive surgery to remake the body in the social image of that gender. Such efforts at "correction" not only violate the child but lend support to the idea that gender has to be borne out in singular and normative ways at the level of anatomy" (Butler, 2004: 63).

For Butler, the practice of genital repair surgery is not only about a pain which is hurt and sore for the child (as in some cases such an operation could result in the loss of child sexual function permanently), but it is also about the change of what the child will be, especially with the "evolved" anatomy because one's body effectively determines the gender identity. Thus in fact, gender, once again, can be related to a condition of a cultural process in the construction of the body or identity of an individual, so that it is therefore open to all possibilities of change.

\section{CONCLUSION}

Based the film and the Butlerian reading, it can be taken important point about how intersex is normalized and being played by social construction. This also simply exposes how gender is constructed by the sex while it also works through performance and performativity. As a construction, gender can be deconstructed and intersex is a fact to reveal this flaw. Conclusively, from those arguments and suggestions, it can be understood that Butler looks to designate that sex cannot be utilized to determine someone's gender and particularly gender is unstable because of its repetitive performances. Consequently, by looking at the case of an intersex, it exposes the thought-provoking situation that an intersex rejecting surgery operation can be analogous rejecting the social construction, but it is a way to set a freedom from the jail of gendering toward someone's gender. The intersex can (n)either man (n)or 
woman. Having two sexes provides the infinitive probabilities to re/deconstruct and perform undetermined gender as (s)he likes. Doing gender in fluid and dynamic condition seems to demonstrate that gender is unsteady and it can be undone. In modest expression, something to infer, Butler signposts the unstable gender through intersex case in an account of undoing gender.

\section{REFERENCES}

Beauvoir, Simone de. 1972. The Second Sex (ed. H. M. Parshley). Harmondsworth: Penguin Books.

Brady, Anita \& Tony Schirato. 2011. Understanding Judith Butler. London: SAGE Publications.

Butler, Judith. 1987. Variations on Sex and Gender: Beauvoir, Wittig and Foucault', in Seyla Benhabib dan Drucilla Cornell (ed) Feminism as Critique: Essays on the Politics of Gender in Late-Capitalist Societies. Cambridge: Polity Press.

Butler, Judith. 1990. Gender Trouble: Feminism and Subversive Identity. London \& New York: Routledge.

Butler, Judith. 1993. Bodies that Matters: On the Discursive Limits of "Sex". New York: Routledge.

Butler, Judith. 2004. Undoing Gender. London: Routledge.

Creighton, S. M. \& Liao, L. M. 2004. Changing Attitudes to Sex Assignment in Intersex. British Journal of Urology International, 93: 659-664.

Derrida, Jacques. 1997. Of Grammatology (trans. Gayatri Chakravorty Spivak). Baltimore: The Johns Hopkins University Press.

Freud, Sigmund. 1933. Femininity in Standard Edition of the Complete Psychological Works of Sigmund Freud (Vol.22, 1960, trans. \& ed. J. Strachey). London: The Hogarth Press.

Harper, Chaterine. 2007. Intersex. New York: Berg.

Lopez, Tyler. 2014. What does Intersex Mean? retrieved from http://www.slate.com/blogs/outward/2014/11/20/taylor_lianne_chandler_com es_out_as_intersex_what_is_intersex.html, on 31 May 2015, at 9 am.

Nietzsche, Friedrich. 1998. On the Genealogy of Morals (Trans. Douglas Smith). Oxford: Oxford University Press.

Preves, Sharon E. 2003. Intersex and Identity: The Contested Self. London: Rutgers University Press.

Salih, Sara. 2002. Judith Butler. London \& New York: Routledge. 